\title{
$\operatorname{arCOS} D E S I G N$
}

\section{Urbanismo tático e intervenções urbanas: aderências e deslizamentos}

Pedro Caetano Eboli Nogueira (PUC-Rio, Brasil)

pceboli@gmail.com

Pontifícia Universidade Católica do Rio de Janeiro

Rua Marquês de São Vicente, 225 - Gávea, Rio de Janeiro - RJ 


\title{
Urbanismo tático e intervenções urbanas: aderências e deslizamentos
}

Resumo: Este artigo se constrói a partir de duas formas de atuação política na cidade. De um lado as lógicas que subjazem ao urbanismo tático, geralmente atribuído a designers e arquitetos, com suas tentativas de solucionar problemas urbanos. Do outro tomamos as intervenções urbanas, próximas das artes plásticas, engajadas em problematizar a urbanidade. Apresentamos alguns exemplos de cada um destes polos fictícios, apontando suas semelhanças e diferenças, com vias a imaginar possibilidades de atuação política nas cidades que troquem estas propriedades.

Palavras-chave: Design participativo, urbanismo tático, intervenções urbanas

\section{Tactical urbanism and urban interventions: adhesions and landslides}

\begin{abstract}
This article is conceived upon two forms of political action in the city. On the one hand, the logic behind tactical urbanism, usually attributed to designers and architects, with their attempts to solve urban problems. On the other side we take the urban interventions, close to the visual arts, engaged in problematizing urbanity. From these fictitious poles, we present some examples of each, pointing out their similarities and differences, aiming to imagine possibilities of political action in cities.
\end{abstract}

Keywords: Collaborative design, tactical urbanism, urban interventions 


\section{Introdução}

Este artigo é um desdobramento da minha fala no seminário Design.com: articulações, expansões e conexões, proferida no dia 30 de maio de 2017 na Escola Superior de Desenho Industrial. Sendo assim, ele é em grande parte baseado no texto que formulei para a mesa, acrescido de algumas das importantes reflexões que foram colocadas pelo público e pelos outros palestrantes. Portanto, o tom coloquial que predomina neste artigo, assim como a supressão de possíveis citações, resulta da procedência deste texto, inicialmente concebido para ser lido em voz alta. A minha fala tematizou algumas das formas de atuação política na cidade, começando pelo urbanismo tático, assunto que me acompanha desde o meu projeto final de graduação e que fez parte da minha dissertação de mestrado. Para que possamos compreender em que consiste o urbanismo tático precisamos fazer uma pequena digressão.

Se tomamos as reformas de Paris empreendidas pelo Barão de Haussmann como marco inicial do Urbanismo, percebemos que esta disciplina tem pouco mais de um século e meio. Desde esta ficção de origem aos dias de hoje assistimos a transformações radicais nas formas como as cidades vêm sendo pensadas e enformadas pelo planejamento urbano. Aos poucos, esta disciplina foi assumindo um caráter cada vez mais técnico e estetizante, sempre centralizado na figura do governo. Os ideais modernos de urbanismo se infiltraram e se materializaram nas mais diversas cidades do mundo. Se olhamos para um caso extremo, como Brasília, vemos que seus preceitos dificilmente permitiriam a emergência de cidades na escala humana.

E não por acaso já nos anos 1960 seus paradigmas seriam alvos de uma série de críticas, das quais poderíamos destacar as de Jane Jacobs, que enalteceu os usos das ruas por pedestres. Mas a emergência do neoliberalismo daria uma nova face às cidades, investidas livremente como mercadorias, como vimos acontecer com o Rio de Janeiro durante as Olimpíadas. Neste contexto elas são tornadas genéricas e os espaços urbanos homogeneizados. A dimensão pública dos espaços é reduzida, com sua substituição pela oferta de serviços e consumo.

\section{0 urbanismo tático}

É justamente neste cenário nefasto que vemos emergir as tais ações de urbanismo tático. Se a burocracia estatal e o livre mercado tiram das mãos dos habitantes as decisões sobre seus espaços públicos, a única forma 
pela qual eles podem ver seus anseios respondidos é se organizando de forma independente e autônoma com relação ao Estado. Assim, as ações de urbanismo tático estão ligadas à apropriação de espaços públicos subutilizados ou terrenos baldios pelas próprias populações locais. $\mathrm{Na}$ maioria das vezes elas envolvem a construção de protótipos urbanos de baixo custo, com natureza efêmera ou permanente. Os espaços urbanos são então ativados pela força do trabalho conjunto em torno de alguma melhoria física local ou proposição de novos usos, envolvendo uma série de processos colaborativos e horizontais de decisão.

Assim, os moradores das proximidades são capazes de opinar e atuar nos espaços públicos de suas regiões, de modo a colocar vizinhos de bairro em contato e empoderá-los. Por este motivo é comum que se atribua ao urbanismo tático um cunho político, uma vez que ele é uma manifestação em que a sociedade civil se emancipa das tutelas do Estado e aponta suas lacunas. Estas ações podem funcionar como uma forma de alertar o Estado para carências dos espaços, e eventualmente informar políticas urbanas de longo prazo. Mas mesmo que muitas vezes seu objetivo seja a posterior implementação, há implícita uma crítica à noção de projeto, pressupondo que testar in loco as soluções urbanas seja melhor que partir das ideias de uma prancheta de arquiteto. Ao mesmo tempo, esta abordagem possibilitaria ao urbanismo tático a construção de cidades na escala humana.

Convém expormos alguns exemplos, de forma panorâmica. Começando por aqueles com natureza mais efêmera podemos destacar o Chair Bombing ${ }^{1}$. Nesta tática urbana que já foi replicada em diversas cidades, os habitantes montam espaços públicos efêmeros com cadeiras, criando novos locais de sociabilidade. Um dado importante do urbanismo tático é justamente esta possibilidade de replicação das ações em diversas localidades, e em cada lugar ele ganha características locais. Nosso segundo exemplo, também ocorrido em diversas localidades, é o Parking Day ${ }^{2}$, em que uma vaga de carro é transformada em um espaço público efêmero. O Build a Better Block ${ }^{3}$, também ocorrido em diversas cidades e de várias formas diferentes, é uma ação em que os vizinhos se juntam num final de semana para melhorar o seu próprio quarteirão.

\footnotetext{
${ }^{1}$ Poderíamos traduzir Chair Bombing como Bombardeio de Cadeiras para o português.

${ }^{2}$ O nome desta tática urbana joga com os dois possíveis significados da palavra inglesa park, que pode tanto significar parque quanto o verbo estacionar.

3 Poderíamos traduzir Build a better block para o português como Construa um quarteirão melhor.
} 


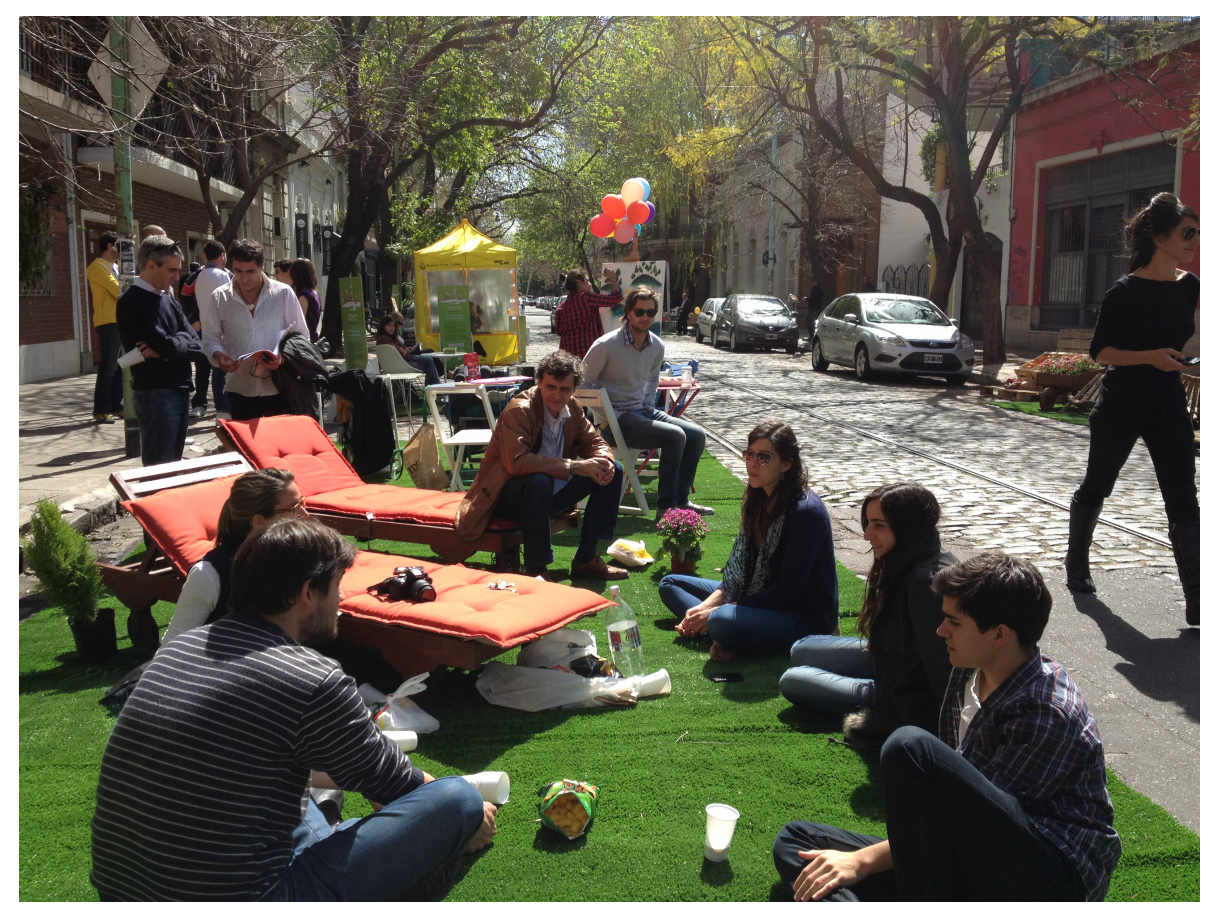

O último exemplo se desenvolve em São Paulo e se chama A Batata Precisa de Você. Ele foi uma resposta a um processo de reurbanização que o Estado aplicou ao Largo da Batata, no bairro de Pinheiros. Essa revitalização acabou esterilizando uma região antes conhecida pela alta circulação de pedestres e pelo comércio popular. Lá a população realiza uma série de atividades e construção coletiva de mobiliário urbano.

Estas ações de urbanismo tático, que emergem de forma mais ou menos espontânea nas mais diversas localidades, vêm ganhando bastante notoriedade e interesse por parte de urbanistas e designers, sendo celebradas como importantes práticas para a urbanidade. E por este motivo o urbanismo tático é tema de eventos e exposições internacionais, dos quais poderíamos destacar a mostra Uneven Growth: Tactical Urbanisms for Expanding Megacities ${ }^{4}$, exibida no Museu de Arte Moderna de Nova Iorque em 2015. Lá foram conceituadas e discutidas várias destas ações. Outro exemplo significativo foi o pavilhão dos Estados Unidos na Bienal Internacional de Arquitetura de Veneza de 2012, dedicado a um mapeamento e categorização de diversas ações de urbanismo tático ocorridas nos Estados Unidos.

\footnotetext{
${ }^{4}$ Poderíamos traduzir Uneven Growth: Tactical Urbanisms for Expanding Megacities por Crescimento desigual: Urbanismos Táticos para megacidades em expansão.
} 
Mas apesar de o urbanismo tático de fato aproximar os cidadãos dos processos decisórios relativos a seus espaços públicos, podemos relacioná-lo a algumas práticas e modos de subjetividade vigentes no neoliberalismo. Por isso gostaria de aprofundar o entendimento da ambiguidade que situa essas ações ao mesmo tempo dentro e fora dos domínios do Estado. Em primeiro lugar, é importante frisar que os urbanismos táticos não poderiam substituir o planejamento urbano centralizado. E nem é este o objetivo. Eles no máximo ajudariam a informar as decisões do poder público, como já aconteceu diversas localidades. Aquilo que surge como urbanismo tático, como protótipo urbano, vem a ser sancionado. Entretanto, neste caso cairia por terra a ideia de que seriam ações totalmente paralelas ao Estado.

Afinal, mesmo acreditando estar se opondo a um Estado autoritário e burocrático que não pensa nos anseios da população, as ações de urbanismo tático acabam por preencher as lacunas deste mesmo Estado. E não podemos ignorar que no âmbito do neoliberalismo os governos procuram se eximir cada vez mais de suas funções e trabalhar no mínimo de seu esforço. Assim, as ações de urbanismo tático se tornam bastante cômodas para o próprio Estado, onde as populações assumem funções que antes eram dele. Fenômenos tais como o desinvestimento do governo, mercantilização do espaço urbano, gentrificação e a intensificação do desenvolvimento desigual, que muitas vezes estão na origem das ações de urbanismo tático - como é o caso do Largo da Batata -, são típicos da aplicação de princípios do neoliberalismo às cidades.

Entretanto, se a resposta a estes fenômenos surge na forma de ações em que os cidadãos colocam suas energias, seu tempo e muitas vezes seu dinheiro na requalificação de espaços públicos, o perigo é que estas mesmas ações encorajem a continuidade ou o aprofundamento destas condições, especialmente da forma como vêm sendo enaltecidas mundo afora. Se o urbanismo tático aparece como uma resposta a um conjunto de políticas de retração do Estado, é possível que estas ações em que a população toma de assalto os espaços urbanos, propondo-lhes soluções, possibilitem que o governo se exima ainda mais de suas funções.

Da mesma maneira, as análises que entendem a informalidade como realidade oposta e apartada da formalidade urbana mostram sua fragilidade. Pois no contemporâneo ambos os pólos são consequência de um certo arranjo flexível gerido pelo próprio Estado, e é de seu interesse mantê-los em coexistência. O Estado neoliberal compreende a gestão da informalidade como parte de suas práticas governamentais, de modo que ela só é coibida quando lhe é interessante. Senão, sua existência é permitida e por vezes 
regulamentada, sancionada, como é o caso de algumas ações do urbanismo tático.

Muitos sociólogos apontam a forma como o neoliberalismo depende da mobilização de energias das populações, e ainda que os urbanistas táticos não estejam sendo obrigados a nada, podemos perceber que há alguns modos de subjetividade intimamente ligados aos regimes neoliberais que parecem basear estas práticas. Pois este regime econômico-político exacerba o papel de uma sociedade civil de laços puros, força motriz da política. E a cada vez que esta sociedade civil deseje estabelecer os paradigmas de sua própria verdade, cabe a ela se insurgir contra o governo. Assim, poderíamos intuir que o combustível para essas energias das populações, que não são postas para agir segundo as forças de uma obrigatoriedade, se dá no âmbito de uma certa produção desejante.

Neste sentido podemos localizar nos discursos do urbanismo tático uma figura consensual. A de que o contemporâneo estaria imerso em uma inércia política, que separa os cidadãos das decisões relativas aos espaços públicos. Então seria preciso romper com esta inércia. Mas talvez este impulso micropolítico acabe se confundindo com os modos de subjetividade neoliberais, aquele do "cada um deve fazer a sua parte", dentro do espírito de responsabilização do indivíduo que caracteriza este regime. Podemos relacionar a esse etos, por exemplo, a ideia de que precisamos vencer uma certa burocracia do Estado e fazermos nós mesmos aquilo que desejamos para a cidade.

Também vemos uma vontade de restaurar laços sociais perdidos, os vínculos com os moradores das redondezas, com os vizinhos, que a insensibilidade e os paradigmas individualistas do contemporâneo teriam esgarçado. Entretanto, seria preciso compreender até que ponto estes traços retóricos não estariam ligados a uma espécie de retorno ao paraíso perdido. Pois não se questiona a qualidade destes laços, eles aparecem como fins em si mesmos. Aqui novamente a ideia de uma sociedade civil de laços puros, de vínculos que não são controlados ou desejados pelo Estado. Poderíamos relacionar este encadeamento retórico às formas de governamentalidade que Michel Foucault (2008, 2008b) denominaria por biopolíticas, intrinsecamente ligadas ao neoliberalismo.

Mas esta mesma ideia de uma sociedade civil contra o Estado traz uma outra figura de consensualidade, pois subentende que cada uma das duas partes compõe uma unidade. Segundo este raciocínio, a partir do momento em que a população se emancipa do Estado se torna fácil decidir o que é melhor para ela. Mas será que o interesse coletivo é um bloco uníssono? Os processos colaborativos e a horizontalidade certamente têm 
limites, ainda que pareçam totalmente democráticos. Neste sentido, é importante recordar que a mera possibilidade aberta para que qualquer pessoa integre as dinâmicas propostas pelo urbanismo tático não implica necessariamente em uma participação efetiva de todos. Nem todos dispõem de tempo e recursos materiais para investi-los na construção coletiva de praças.

Ações como estas podem nos levar a refletir sobre os atos que, ensaiando uma contraposição ao Estado, acabam engrossando o coro de uma agenda de retração e desresponsabilização que a ele é bastante conveniente. As políticas neoliberais dependem desta flexibilidade, em que se complementam a formalidade e a informalidade urbanas, em que as energias populares acabam postas para cobrir suas lacunas. E é neste sentido que o urbanismo tático se situa ao mesmo tempo dentro e fora dos domínios do Estado. Neste contexto, o neoliberalismo parece acolher e se apropriar com bastante desenvoltura de atos presumidamente micropolíticos. Sendo assim, se torna importante pensar os limites de ações políticas que se articulam como uma oposição frontal ao Estado, mas também no registro da solução de problemas urbanos. Eu me pergunto de que forma algumas ações de urbanismo tático já estariam ou poderiam se engajar neste avesso. Para que nos mantenhamos no domínio da política, talvez a procura por questões para a cidade, impassíveis de serem sancionadas pelo governo, pudesse tomar mais espaço. Mas sempre tomando cuidado com o pensamento contemporâneo segundo o qual tudo seria político, que acaba acarretando na dissolução da própria política, pois se tudo é político, nada o é.

\section{Intervenções urbanas}

Como representante desta outra forma de atuação na cidade poderíamos citar os trabalhos de intervenção urbana, mais ligados ao domínio das artes plásticas que do design ou da arquitetura. A partir de alguns trabalhos do Opavivará!, um coletivo carioca de arte que trabalha muito com intervenções urbanas, traço algumas proximidades e distâncias das lógicas que regem as ações de urbanismo tático. Em Pula Cerca, o coletivo colocou escadas para que os passantes pudessem pular as grades da Praça Tiradentes, na época em que ela era gradeada. Esta abordagem tem algo de tática, no sentido de que é totalmente pontual, pensada especificamente para este lugar e realizada in loco. Mas não se trata de uma solução urbana discutida e decidida em comunhão entre os moradores locais, mas de uma proposição efêmera, em que as escadas sugerem novos 
deslocamentos e fluxos no espaço. Se esse uso das escadas não seria uma solução, ela parece mais funcionar no registro de um questionamento, de uma provocação.

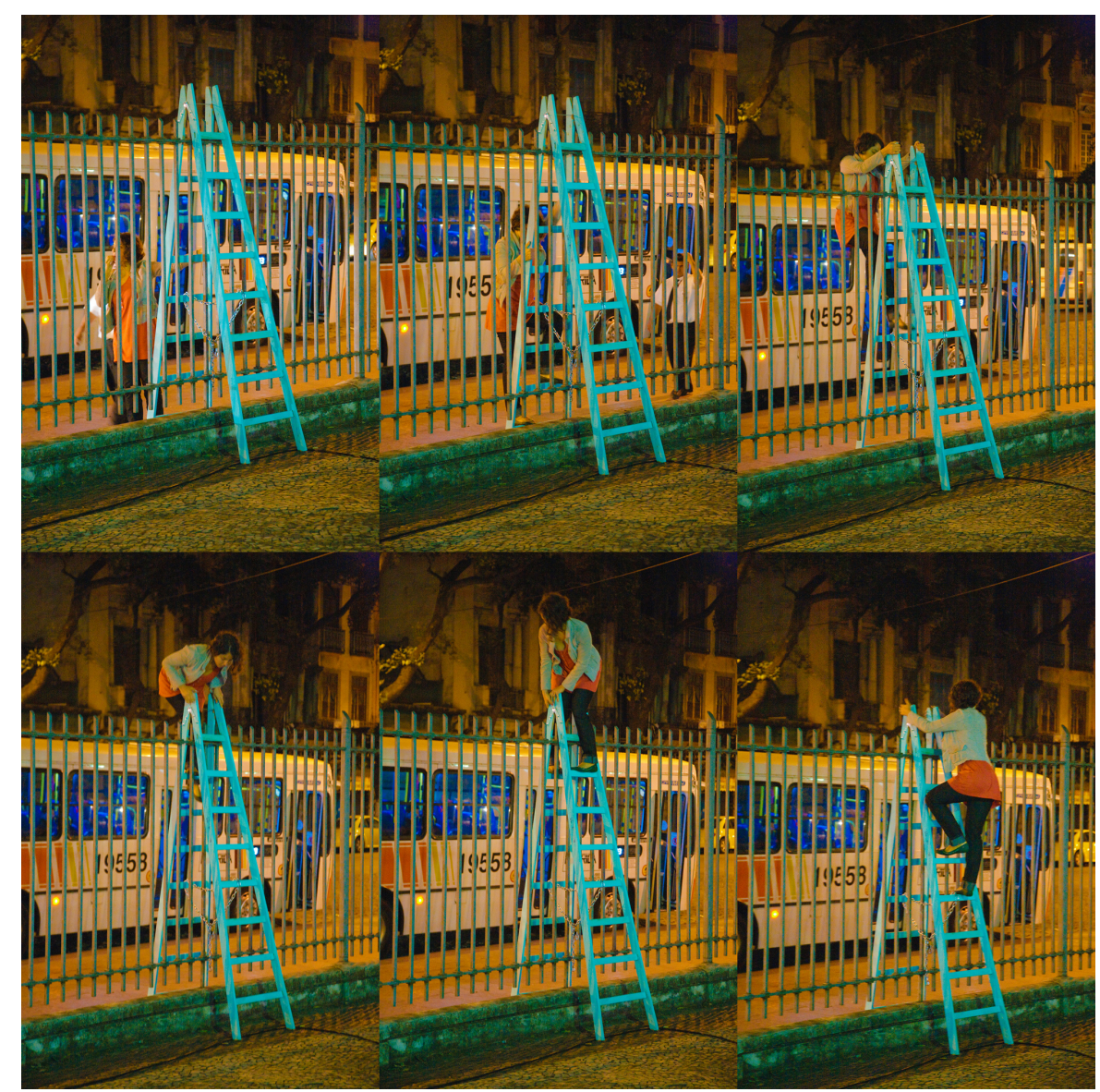

Os membros do coletivo inclusive afirmam que o trabalho teria ajudado na posterior remoção das grades da praça. Esta remoção não pode ser dissociada do processo de gentrificação ainda em curso nas imediações da Praça Tiradentes, em que outras barreiras, muitas delas invisíveis, passam a gerir os fluxos de passantes pela região. E neste processo, a arte está especialmente implicada. Mas ainda que possamos enquadrar esta ação como um impulso de solução urbana, ela surge como uma proposição totalmente fortuita que o coletivo coloca aos passantes. Não há qualquer tentativa de coletivizar a escolha daquilo que será proposto, como nas manifestações de urbanismo tático. Mas será que este este fato subtrai o caráter democrático da ação ou da subsequente remoção das grades da praça? Talvez as intervenções urbanas, ao produzirem problemas para a cidade, lancem mão de uma outra forma de democracia. Ao suspenderem o fluxo normal dos acontecimentos estes trabalhos engajam os passantes em 
possibilidades infinitas de produção de sentidos, e há de fato um devir democrático e emancipatório nesta abertura de potências.

O trabalho Na Moita é o segundo e último exemplo. Assim como algumas das ações de urbanismo tático de que eu falei anteriormente, este trabalho foi apresentado em diversos lugares, como uma tática replicada. A ideia surgiu daquelas moitas urbanas que poderíamos encontrar em qualquer cidade do mundo, espaços efêmeros onde as pessoas cometem atos ilícitos ou imorais do corpo, tais como o sexo e o uso de drogas. O coletivo passou então a reproduzir estas moitas, seja nos espaços da arte ou da cidade, criando um outro recanto de sociabilidade que parece se mimetizar na paisagem. Ao meu ver o trabalho não está interessado em criar soluções para os espaços urbanos, mas engajado em questionar todo um regime de moralização dos corpos através dos olhares, entendendo que a vida nas cidades tenha multiplicado estes olhares. No contemporâneo, inclusive, eles encarnam até mesmo em autômatos, tais como câmeras de segurança ou de celular.

O trabalho fala de uma força flexível, que não atua de forma proibitiva, mas recalca os prazeres do corpo para locais refugiados do olhar. Talvez se trate de um poder invisível, semelhante àquele que agora gere os corpos que circulam em uma Praça Tiradentes sem grades. Mas ao deslocar estas moitas urbanas para a experiência da arte, o coletivo dá a ver que as disposições espaciais e materiais não dependem unicamente da intencionalidade de um sujeito. $\mathrm{E}$ isso não significa dizer que elas são espontâneas e casuais, mas perceber que muitas delas são fruto de uma certa cartografia de forças e poderes. Esta leitura permitiria até mesmo imaginar que as diversas ocorrências do urbanismo tático ao redor do mundo, de forma tão semelhante, não sejam tão espontâneas como vêm sendo divulgadas. Mas que elas talvez provenham de um dispositivo complexo de poderes, de estratégias sem sujeito, que refletem uma certa forma de governamentalidade intimamente relacionada ao neoliberalismo nas cidades.

Mas Na Moita também permite imaginar que as disposições espaciais "espontâneas", apropriadas pelo coletivo, refletem uma certa complementaridade entre poder e resistência. Pois se de um lado não podemos imaginar a existência destas moitas urbanas fora da incidência dos olhos do poder sobre os corpos, por outro elas expressam justamente uma possibilidade de transgressão. Pois estas moitas são totalmente permeáveis, o único refúgio que elas oferecem é aquele de uma opacidade, de uma invisibilidade momentânea e frágil que dá aos corpos a possibilidade de um prazer público. 


\section{Considerações finais}

É precisamente na produção destas fraturas na ordem do sensível, no debandar dos sentidos, sensações e experiências naturalizadas, no descentramento daquilo que une o sujeito a si mesmo, que as intervenções urbanas engendram suas formas micropolíticas. A política vista como assunto concernente aos sujeitos, não mantendo, portanto, qualquer vínculo ou tentativa de contraposição às estruturas dos governos. Mas, como nos ensina Félix Guattari (1987), há uma relação transversal entre uma micropolítica das subjetividades e a macropolítica. Pois uma não se legitima ou perpetua sem a outra, e ainda que de maneira pouco unívoca ou previsível, é inegável que estas duas esferas se interpenetrem e modifiquem mutuamente. Assim, no âmbito de um desejo político talvez haja uma permeabilidade frutífera entre as lógicas constitutivas do urbanismo tático e os questionamentos que movem as intervenções urbanas.

Sendo assim, se mostra importante tensionar alguns dos pressupostos que regem as ações de urbanismo tático. Especialmente quando se tratam de movimentos em que a arquitetos e designers tomam a dianteira, se lançando em um desejo de solucionar problemas urbanos. Antes de advogar um caráter político intrínseco e purificador a estas práticas, é importante indagar sobre a sobre a possibilidade de estes mesmos atores estarem servindo como pontas de lança em processos de gentrificação ou participando de um processo mais geral de flexibilização neoliberal dos territórios da cidade. E é inegável que as artes plásticas compartilhem deste perigo iminente.

A própria ideia de que a ocupação da cidade é um ato intrinsecamente político traz alguns problemas. A quem é permitida a ocupação da cidade? E quando a ocupação da cidade por uns é coextensiva à expulsão de outros? Se solucionar os problemas da cidade significa se colocar a serviço do Estado, então, do ponto de vista político, é importante deixar sempre presente um pensamento de suspensão, em que os sentidos não estejam todos óbvios e acertados. Pois a atividade política, como nos ensina Jacques Rancière $(1996,2005)$ não tem nada a ver com os fins atingidos, ela é algo como uma prática performática sem qualquer télos ou modelo de eficácia. 


\section{Referências}

FOUCAULT, Michel. Segurança, território, população: curso dado no Collè ge de France (1977-1978). Sã o Paulo: Martins Fontes, 2008.

FOUCAULT, Michel. Nascimento da biopolí tica: curso dado no Collè ge de France (1977-1978). Sã o Paulo: Martins Fontes, 2008.

FOUCAULT, Michel. Microfí sica do poder. Rio de Janeiro: Graal, 2009.

GADANHO, Pedro. Uneven Growth: Tactical Urbanism for Expanding Megacities. Nova Iorque: The Museum of Modern Art, 2014.

GUATTARI, Felix. Revoluç ã o molecular: pulsaç õ es politicas do desejo. Sã o Paulo: Brasiliense, 1987.

JESSOP, Bob. The State, Politics, and Civil Society. Londres: Routledge, 1999.

LYDON, Mike \& GARCIA, Anthony. Tactical Urbanism Short-Term Action for Long-Term Change. Washington, DC [u.a.]: Island Press, 2015.

RANCIÈRE, Jacques. A partilha do sensí vel: esté tica e polí tica. Sã o Paulo: Ed. 34, 2005.

RANCIÈRE, Jacques. O desentendimento: política e filosofia. Sã o Paulo: Ed. 34, 1996. 


\section{Como citar}

NOGUEIRA, Pedro C. E. Urbanismo tático e intervenções urbanas: aderências e deslizamentos. Arcos Design. Rio de Janeiro: PPD ESDI - UERJ. Edição Especial Outubro 2017. pp. 89-101.

Disponível em: [http://www.e-publicacoes.uerj.br/index.php/ arcosdesign]

DOI 10.12957/arcosdesign.2017.30943

\section{(c) (1) (8)(2)}

A Revista Arcos Design está licenciada sob uma licença Creative Commons Atribuição - Não Comercial - Compartilha Igual 3.0 Não Adaptada. 